\title{
Critical Success Factors in ERP Upgrade Projects
}

\author{
David L. Olson' and Fan Zhao ${ }^{2}$ \\ 1 Department of Management, University of Nebraska, Lincoln, NE \\ 68588-0491 USA \{dolson3@unl.edu\}, \\ WWW home page: ait.unl.edu/dolson \\ 2 Department of Management, University of Nebraska, Lincoln, NE \\ 68588-0491 USA \{fzhao@unlnotes.unl.edu\}
}

\begin{abstract}
Enterprise information systems have proven invaluable in improving the administration of organizations. Since the turn of the Century, enterprise system upgrades have become important. This study reports interviews with the CIOs of six institutions that have undergone (or are undergoing) enterprise system upgrades. Each interview discussed the process used to upgrade. Focus was on discussion of major critical success factors. This paper reviews critical success factors reported in the literature for enterprise system installation projects, and adds to that body of knowledge by preliminary views of factors important in successful enterprise system upgrade projects.
\end{abstract}

\section{Introduction}

Enterprise systems have spread rapidly among organizations. According to AMR research [1], ERP market size was $\$ 47.88$ Billion in 2004. Although ERP systems offer a great deal, implementation success is far from assured. Statistics show that more than $70 \%$ of ERP implementations fail to achieve their corporate goals [2] and the number of horror stories about failed or out-of-control projects is growing [3]. Previous research has shown that failure to understand the business implications of ERP systems is related to implementation failure [4, 5]. Despite great technical challenges, the biggest problems in ERP implementations are business problems [6].

Recent reviews [7] suggest that most existing ERP research focuses on selection and implementation, not on ERP's post-implementation impacts. Selection and implementation are critical areas, and numerous valuable insights have been studied by many researchers, to include Akkermans \& Van Helden [8], Gefen [9], Hong and

Please use the following format when citing this chapter: 
Kim [10] and Robey et al. [11]. These studies have cited the factors given in Table 1 as influential in ERP installation success.

According to Staehr et al. [12], the ultimate impacts of ERP on the organization once the system has been implemented and has been "shaken down" - are not as thoroughly researched. Therefore, understanding post-implementation of ERP will help organizations succeed longer after the ERP implementation. ERP upgrade is one of the major activities in the post-implementation stage of ERP implementation [13]. Every three years, a major ERP upgrade and several small upgrades are typically needed to keep the system running smoothly. Organizations will spend a significant amount of money on each ERP upgrade project. Without comprehensive understanding of ERP upgrade concepts in the organizational environment may lead to terrible nightmares, and even result in irretrievable disaster. Therefore, the aim of this research focuses on what factors are associated with ERP upgrade success.

Table 1: Critical Success Factors Cited in ERP Installation

\begin{tabular}{|r|r|r|}
\hline Relationships with consultants & Top management support & Package customization \\
\hline Core team characteristics & Project champion & Project management \\
\hline Business process reengineering & User involvement & Implementation approach \\
\hline Change management & Package choice & Add-on module integration \\
\hline User training & Module choice & A clearly stated business case \\
\hline
\end{tabular}

There are several reasons why this study is important. First, each ERP upgrade project costs a significant amount of money. For example, a Midwest university spent over $\$ 2$ million on a recent ERP upgrade project. While first time ERP implementation happens only once, ERP upgrades will happen many times after the first ERP implementation (probably once every three years). Therefore, the cost of ERP upgrade is continuous along with the usage of the ERP system in the organization.

Second, relatively little research attention has been given to ERP software upgrade. One possible reason could be that upgrade is perceived to be a smaller project (compared to first time ERP implementation), and another reason could be that little theory has been developed regarding the topic of ERP upgrade. However, ERP upgrade is one of the important activities in the ERP software lifecycle, and an effective and efficient implementation of ERP upgrade has a tremendous impact on an organization's continuous business process improvement.

Third, little progress has been made in identifying relative importance of success factors in each ERP upgrade stage. Understanding the relative importance of success factors in each stage can help IT managers emphasize on dominant issues during the ERP upgrade projects. Especially when there are needs to make decisions about trade-offs among different upgrade activities, IT managers can focus on the most important factors other than less important factors in each upgrade stage. 


\section{ERP Upgrade}

ERP upgrades are mainly intended to take advantage of new technologies and business strategies to ensure that the organization keeps up with the latest business development trends. Therefore, the decision to upgrade ERP is usually not driven by code deterioration or anticipated reduction in maintenance costs alone, but by different purposes. According to an AMR study [14], 55\% of upgrades were voluntary business improvements triggered by the need for new functionality, expansion or consolidation of systems; $24 \%$ of upgrades were triggered by technology stack changes; $15 \%$ of upgrades were forced by de-support of the running version of software to avoid vendor support termination [15]; and $6 \%$ of upgrades were triggered by bug fixes or statutory changes.

The cost of ERP upgrades is high [16]. Swanton [14] mentioned that the cost of each upgrade includes: $50 \%$ of the original software license fee and $20 \%$ of the original implementation cost per user, which means over 6 million dollars for a 5,000-user system. Typically, each ERP upgrade requires eight to nine months of effort with a team the equivalent of one full-time employee per 35 business users. The ERP-adopting organization does not have to develop and re-write the ERP system itself but rather it replaces (or upgrades) the old version with a readily available new version from the ERP vendor. However, a lack of experience may cause the costs and length of the upgrade project to approach or even exceed those of the original ERP implementation effort. Collins [17] listed some general benefits for organizations from ERP upgrades:

- Eligibility for Help Desk Support: Most of ERP software vendors stop providing technical support 12 to 18 months after the next version becomes available. Therefore, keeping upgrade with the pace of ERP vendors will guarantee the support for the system from the vendors.

- Solutions for Outstanding "Bugs" or Design Weaknesses: It is impossible to guarantee spotless and error-free ERP systems after the implementations even though vendors will conduct many different testing processes to eliminate the happenings of errors in the system before the leasing time. "The majority of software bugs are resolved and delivered either fix-by-fix, or all-at-once as part of the next release version of the ERP package." In this case, upgrades will be beneficial to the organizations in problem solving.

- New, Expanded, or Improved Features: ERP software provides organizations the knowledge and strength (i.e. best practices) from the vendors. ERP upgrades provide organizations future enhancement from the vendors to give the organizations better opportunities to catch up the current business development, improve their processes and build more efficient business models with new functions, new features and new processing styles provided in the upgraded ERP versions.

Collins [17] described a four phase upgrade procedure. Phase one included impact analysis and initial upgrade. Impact analysis is to conduct impact analysis to evaluate the upgrade version and identify the differences between customized applications and new applications in the new version. Initial upgrade then can help 
merge the customized application and new application together smoothly. Phase two is solution development, in which "all modifications that were overwritten are redeveloped and retested". Acceptance /performance testing is the phase three to finally test the whole system. Finally, production conversion is conducted to run the new version in the organization. This model is useful in that it distinguishes between the 'phases' of change which the organization passes through as it implements change, and the 'processes' of change, i.e. the methods applied to get the organization to the desired state. The model progresses as follows:

\subsection{Assessment Phase}

For the manager, the change process begins when questions are asked about what the originators of the proposal actually want to do. It begins with a general review of the organization, and it is relevant to organizational health, which is itself to do with motivation. By examining motives, managers should find out both positive and negative reasons for introducing change by asking all kinds of questions related to the change, such as what are the desired outcomes? What are the problems? How does the project fit with the strategy of the organization? What is the likely effect on the organization? What is to be the role of the manager? Outcomes of the assessment phase include:

- Identification of what changes are required,

- Justification of changes,

- Identification of resources required.

\subsection{Planning Phase}

The organization should make a detailed plan regarding all aspects of the resources of the organization. This includes staffing and personnel implications, structural implications, technical features and requirements, hardware and software arrangement, training plans, communication plans, etc. Outcomes of the planning phase include:

- Clarification of goals and objectives for each milestone,

- Identification of specific activities required to undertake desired change,

- Commitment obtained from stakeholders,

- Identification of support required to enable change to occur,

- Identification of staff development needs,

- Design of feedback mechanism, 
- Review of general organizational implications.

\subsection{Action Phase}

Changes identified are agreed upon and implemented. Actions and outcomes of the action phase can include:

- Putting the personnel in place,

- Communicating with the entire organization regarding activity results,

- Adjusting and refining changes where necessary,

- Reviewing the general organization implications,

- Putting the change into operation.

\subsection{Renewal Phase}

The initial activity in this phase is to place the new system into operation. That tends to be very short in duration. But the renewal phase also offers the prospect of assessing the success and impact of the change, it also helps make changes permanently effective within the organization. Activities can include:

- Monitoring and evaluating changes,

- Results and outcomes from change communicated throughout the organization,

- Continuous development of employees through training, education,

- Ongoing monitoring and evaluation.

\subsection{Method}

Six IT managers were interviewed with a semi-structure interview format to explore key successful factors for ERP upgrade. The purpose of this study is to gain an initial understanding of key factors in ERP upgrades. Structured interviews were conducted with six CIOs of a diverse set of organizations.

\subsection{Organizations}

A. Color Imaging is one of the largest independent toner manufacturers in the world. It is a middle size company with over 100 employees. They adopted 
an Impact 4.0 (Syspro) ERP system in 1998, and upgraded to Syspro 6.0 to obtain new functionalities and features. This upgrade project took 6 months.

B. DePaul University is a university in Chicago, Illinois, using ERP for administration. Their initial ERP system (PeopleSoft) was adopted in 1999. The upgrade project took about nine months. In 2003 they began their upgrade planning, due to the end of service support of the particular software system used, and because of the desire for greater system functionality.

C. Lincoln Electric System is an electric utility distributor in Lincoln, Nebraska. They initially adopted an SAP in 1999, upgrading to R/3 4.7 in 2004. This project took three and one-half months. The primary reason cited for the upgrade was difficulty in obtaining useful support from SAP for an older version of their software.

D. Molex is the world's second-largest manufacturer of electronic, electrical and fiber optic interconnection products and systems with 16,241 employees and 115 operations on six continents. They adopted an ERP R/3 system at Corporate World Headquarters (Singapore) in 1996, and installed it in the Lincoln branch in 1998. In 2003 they upgraded from version 3.01D to version $4.6 \mathrm{~B}$ in a five month project. The upgrade was adopted to gain new functionality, as well as anticipation of an announcement by SAP that they would stop support in a few years if an upgrade wasn't undertaken.

E. The State of Nebraska uses ERP to join many diverse information systems in support of the administration of state government. They adopted J.D. Edwards' OneWorld 3 system in 2002. However, the service for this system was due to expire, and the newer package had added functionality enabling the State to record operations that were cumbersome in the old system. The upgrade project was underway, and was expected to take about nine months.

F. The University of Nebraska uses ERP for administration of all elements, including four distinct University programs. They adopted an SAP package in 1999. In 2004 the support contract was about to expire, and better technical support was desired (it took up to two months to get support for the old version). The upgrade project was underway, and was expected to take about 11 months.

\section{Results}

The assessment phase took about two months. Five months were spent in the planning phase, to include the simulation sandbox. The overall project took 11 months, and the implementation was again very short, so about four months may be inferred for the action phase. Valuable insight was provided about the need to focus training on how the system should be used to help the organization rather than focus on software. 


\subsection{Recapitulation of the Upgrade Process}

These upgrade projects took between 2.5 months (a local system, with no customization) to 11 months (a more complex organizational structure with heavy training requirements). Customization may be needed by organizations, but will incur a cost in time (and thus money). The assessment phase was often quite short, although larger organizations took longer because of the need to obtain corporate approval. Planning and action phases were relatively consistent. We would conclude that upgrade projects involve lower levels of risk and uncertainty (and thus variance) than initial installations because the organization is very familiar with what the system should do. The renewal phase (putting the system on-line) was very short. With proper project management, overnight or a weekend was proven possible.

\subsection{ERP Upgrade Critical Success Factors by Phase}

Each organization was asked to select those factors that they found important by project phase. These results are given in Table 2.

The six organizations were quite consistent in their selection of critical success factors by phase. Business vision was selected by all organizations in the assessment phase. Top management support was selected by four the six organizations in this phase. One organization also selected communication.

In the planning phase, there was unanimity that project management was the most important success factor. Communication was selected as second in importance by five of the organizations. Two selected external support, which would emphasize the need to work with vendors.

In the action phase, project management continued to be selected as important (five of six organizations). One organization identified the need for a positive organizational culture. This was the multinational organization. The other organizations were smaller in geographical scope. Training was cited by five of the six organizations (the other selected the value of a project champion). Four organizations cited the need for user involvement. Customization was tabbed by one organization, the only appearance on this list, although it clearly was cited as an important factor in the reviews of the upgrade process.

The renewal phase was quite short in most of the cases. All organizations (even those currently undergoing their upgrade projects) cited the need (or expectation) that user involvement was important. Two also cited the need for external support (from vendors). 
Table 2: Critical Factors by Phase

\begin{tabular}{|c|c|c|c|}
\hline Phase & $1^{\mathrm{st}}$ & $2^{\text {nd }}$ & $3^{\text {rd }}$ \\
\hline Assessment & $\begin{array}{l}\text { A-Top support } \\
\text { B-Business vision } \\
\text { C-Business vision } \\
\text { D-Top support } \\
\text { E-Business vision } \\
\text { F- Top support }\end{array}$ & $\begin{array}{l}\text { A-Business vision } \\
\text { B - Top support } \\
\text { D- Business vision } \\
\text { F- Business vision }\end{array}$ & F - Communication \\
\hline Planning & $\begin{array}{l}\text { A-Project mgmt } \\
\text { B-Project mgmt } \\
\text { C-Project mgmt } \\
\text { D - Project mgmt } \\
\text { E-Project mgmt } \\
\text { F-Project mgmt }\end{array}$ & $\begin{array}{l}\text { A-Ext. support } \\
\text { B-Communication } \\
\text { C-Communication } \\
\text { D-Communication } \\
\text { E- Communication } \\
\text { F-Communication }\end{array}$ & E-Ext. support \\
\hline Action & $\begin{array}{l}\text { A-Project mgmt } \\
\text { B - Project mgmt } \\
\text { C-Project mgmt } \\
\text { D - Org. culture } \\
\text { E-Project mgmt } \\
\text { F- Project mgmt }\end{array}$ & $\begin{array}{l}\text { A - Training } \\
\text { B - Proj. champion } \\
\text { C - Training } \\
\text { D - Training } \\
\text { E - Customization } \\
\text { F - Training }\end{array}$ & $\begin{array}{l}\text { A-User involved } \\
\text { C-User involved } \\
\text { D-User involved } \\
\text { E-Training } \\
\text { F- User involved }\end{array}$ \\
\hline Renewal & $\begin{array}{l}\text { A-User involvement } \\
\text { B-User involvement } \\
\text { C-User involvement } \\
\text { D-User involvement } \\
\text { E-User involvement } \\
\text { F-User involvement }\end{array}$ & $\begin{array}{l}\text { A - Ext. support } \\
\text { B - Ext. support }\end{array}$ & \\
\hline
\end{tabular}

\section{Conclusions}

ERP upgrade projects have grown in importance, as vendors are seeking to generate revenue through improved systems. The reticence of vendors to support old systems was noted by multiple organizations in this study. (The value of improved functionality was also noted.) 
Upgrade projects seem to be much more controllable than initial ERP installation projects. This should be expected due to the experience organizations gain with their original systems. All of the organizations seemed to do something that fit the theoretical model of an upgrade project that we used. Assessment, planning, and action phases were present to at least some degree. The renewal phase noted by the six organizations involved very smooth turnover. A limitation of the study is that future implications were not yet available in all cases (problems may crop up later), although all organizations credited strong planning and project management as ways to assure smooth transitions.

Of the list of eleven critical success factors provided, nine were selected for one or more phases. Top support and business vision seemed critical in assessment. Project management and communication were usually selected as critical in the planning phase. Project management, training, and user involvement were commonly selected in the action phase. User involvement and external support were cited in the renewal phase. Some factors were selected rarely (external support, project champion), indicating that they may apply in specific circumstances. Two of the eleven factors were not selected (business process reengineering, internal support). That might be because business process reengineering is less important in upgrades, because the initial ERP selection included most of that. (Selecting processes was, however, mentioned as part of the upgrade process by one organization.) Internal support might have been inferred, and probably overlaps with user involvement and top management support. One organization selected customization (which was not on our list), reflecting the importance of this feature that was noted by a number of other organizations.

ERP upgrade projects were shown to be less problematic that initial ERP installations, which in retrospect, may seem obvious. However, the six cases clearly show that some factors are more critical in different phases. And clearly careful planning is needed to attain success.

\section{References}

1. AMR, AMR Report (2005); Available at http://www.amrresearch.com.

2. Standish Group, Third Quarter Research Report (2004); Available at http://www.standishgroup.com/index.php, accessed May 2005.

3. D. Olson, Managerial Issues of Enterprise Resource Planning Systems (New York: McGraw-Hill Companies 2004).

4. B. Mendel, Overcoming ERP Project Hurdles, InfoWorld 21(29), (1999).

5. K. Kumar and J. Van Hillgersberg, ERP experience and evolution, Communications of the $A C M$ 43(4), 23-26 (2000).

6. T. Davenport, Putting the Enterprise into the Enterprise System, Harvard Business Review 76, 121-131 (1998).

7. F.R. Jacobs and E. Bendoly, Enterprise Resource Planning: Developments and Directions for Operations Management Research, European Journal of Operational Research 146(2), 233-240 (2003). 
8. H. Akkermans and K. Van Helden, Vicious and Virtuous Cycles in ERP Implementation: A Case Study of Interrelations between Critical Success Factors, European Journal of Information Systems 11, 35-46 (2002).

9. D. Gefen, Nurturing Clients' Trust to Encourage Engagement Success During the Customization of ERP Systems, OMEGA--International Journal of Management Science $\mathbf{3 0}$, 287-299 (2002).

10. K.-K. Hong and Y.-G. Kim, The Critical Success Factors for ERP Implementation: An Organizational Fit Perspective, Information and Management 40(1), 25-40 (2002).

11. D. Robey, J.W. Ross, and M.C. Boudreau, Learning to Implement Enterprise Systems: An Exploratory Study of the Dialectics of Change, Journal of Management Information Systems 19(1), 17-46. (2002).

12. L. Staehr, G. Shanks, and P. Seddon, Understanding the Business Benefits of Enterprise Resource Planning Systems, In the Proceedings of the 8th Americas Conference on Information Systems, R. Ramsower and J. Windsor (Eds.), Dallas, TX, (2002), pp. 899-905.

13. F. Nah, S. Faja, and T. Cata, Characteristics of ERP Software Maintenance: A Multiple Case Study, Journal of Software Maintenance and Evolution: Research and Practice 13, 399$414(2001)$.

14. B. Swanton, Build ERP Upgrade Costs into the Business Change Program - Not the IT Budget, Computer Weekly 9/21/2004, 28 (2004).

15. R. Craig, Laurier Enterprise System Upgrade, International Conference of Information Systems, Charlotte, USA (1999).

16. N. Montgomery, Build Your Business Case for Upgrades by adding Functionality, Computer Weekly, 2/10/2004, 16 (2004).

17. K. Collins, Strategy and Execution of ERP Upgrades, Government Finance Review 15(4), 43-47 (1999). 